\title{
COLORED POTATOES (SOLANUM TUBEROSUM L.) DRIED FOR ANTIOXIDANT-RICH VALUE-ADDED FOODS
}

\author{
BALUNKESWAR NAYAK ${ }^{1}$, JOSE DE J. BERRIOS2 ${ }^{2}$, JOSEPH R. POWERS ${ }^{3}$, JUMING TANG ${ }^{1,4}$ and YULIN JI ${ }^{1}$ \\ 'Department. of Biological Systems Engineering, Washington State University, Pullman, WA 99163 \\ ${ }^{2}$ Processed Foods Research Unit, WRRC, USDA-ARS, Albany, CA \\ ${ }^{3}$ School of Food Science, Washington State University, Pullman, WA
}

\begin{abstract}
${ }^{4}$ Corresponding author.
TEL: +1-509-335-2140;

FAX: +1-509-335-2722;

EMAIL: jtang@wsu.edu
\end{abstract}

Received for Publication November 17, 2009

Accepted for Publication April 12, 2010

doi:10.1111/j.1745-4549.2010.00502.x

\begin{abstract}
Colored potatoes (Solanum tuberosum L.) are a significant source of antioxidants from polyphenols, carotenoids and ascorbic acid. In this study, the retention of total antioxidants in fresh colored potatoes and processed potato flakes prepared as potential ingredients for snack foods was studied. Total antioxidant capacity, total phenolics and total anthocyanins were higher in purple potato flesh compared with those from red, yellow and white potato cultivars. Peeled purple potatoes were blanched and dehydrated by freeze drying (FD), drum drying and refractance window drying to prepare potato flakes. Results showed no significant losses in total antioxidant capacity and total phenolic content in flakes in all drying methods obtained under study. However, 45,41 and $23 \%$ losses in total anthocyanins content were observed in potato flakes after FD, drum drying and refractive window drying, respectively. Colored potatoes could provide an excellent source of antioxidant-rich ingredient for the production of nutritionally enhanced food products.
\end{abstract}

\section{PRACTICAL APPLICATIONS}

Over $50 \%$ of potato sales in U.S. are to processors for French fries, chips, dehydrated potatoes and other potato products, while the remainder goes to the fresh market. Potato consumption can be increased through the development of value-added products with enhanced nutrition. In the present study, we found that purple colored potatoes are rich in phenolic compounds that have antioxidant capacity. Different drying methods also retained the antioxidant capacity of the colored potato. Most importantly drum drying that is mostly used in potato industries to produce potato flakes retained most of the phenolic antioxidant compounds. Hence, the use of flours from colored potatoes may be used to produce products such as snack foods high in antioxidants and attractive natural colors so that the developed potato products can be marketed as healthy foods.

\section{INTRODUCTION}

Antioxidant phytochemicals in plants have recently attracted great attention from the research community, food industry and consumers. A large number of scientific papers report the important role of phytochemicals in preventing many chronic diseases that are related to oxidative stress caused by free radicals (Van den berg et al. 1999). Free radicals are associated with cancer, inflammation, atherosclerosis and ageing (Halliwell et al. 1992). Phytochemicals, such as polyphenols in fruits and vegetables, possess high antioxidant activities that control degenerative oxidative reaction caused by reactive oxygen in living tissues (Kaur and Kapoor 2001; Lachman et al. 2005). It has been reported that phenolic compounds including anthocyanins (Fig. 1) have potential to scavenge free radicals (Kalt et al. 1999). Antioxidant capacity has been highly correlated to the amount of phenolic compounds and anthocyanins present in dark colored fruits and vegetables (Prior et al. 1998; Brown et al. 2003). Among the common commercial fruits, blueberries have the largest antioxidant 
<smiles>COc1cc2c(O)cc(O)cc2[o+]c1-c1ccc(O)cc1</smiles>

Pelargonidin-3-glucoside<smiles>COc1cc2c(O)cc(O)cc2[o+]c1-c1cc(O)c(O)c(O)c1</smiles>

Delphidin-3-glucoside<smiles>COc1cc2c(O)cc(O)cc2[o+]c1-c1ccc(O)c(O)c1</smiles>

Cyanidin-3-glucoside<smiles>COc1cc(-c2[o+]c3cc(O)cc(O)c3cc2O)cc(O)c1O</smiles>

Petunidin-3-glucoside<smiles>COc1cc2c(O)cc(O)cc2[o+]c1-c1cc(OC)c(O)c(OC)c1</smiles>

Malvidin-3-glucoside<smiles>COc1cc(-c2[o+]c3cc(O)cc(O)c3cc2O)ccc1O</smiles>

Peonidin-3-glucoside
FIG. 1. STRUCTURE OF ANTHOCYANINS

$\mathrm{G}$, glucosides. capacity (Wang et al. 1996). It has also been reported that Andean purple corn and red-fleshed sweet potato have even higher antioxidant capacity and antiradical activity than blueberries and higher or similar content of phenolic compounds and anthocyanins (Cevallos-Casals and CisnerosZevallos 2003).

Potatoes (Solanum tuberosum L.) have traditionally been perceived by consumers as starchy food. Lewis et al. (1998) and more recently Jansen and Flamme (2006) have reported phenolic, anthocyanin and flavonoid contents of different varieties of colored potato cultivars and breeding clones. Colored potatoes have attracted the attention of investigators as well as consumers because of their antioxidant activities, taste and appearance. The antioxidant activity in colored potatoes is associated with the presence of polyphenols anthocyanins, flavonoids, carotenoids, ascorbic acid, tocopherols, alpha-lipoic acid and selenium (Lachman et al. 2005). Therefore, colored potatoes have the potential to be one of the richest sources of antioxidants in the human diet. Brown (2005) reported 0.5 to $1 \mu \mathrm{g}$ of carotenoids per gram fresh weight (FW) in white, up to $20 \mu \mathrm{g}$ per gram FW in deeply yellow to orange and 0.09 to $0.38 \mathrm{mg}$ of total anthocyanins per gram FW in purple and red potato cultivars. The investigator also reported that on an average, potato contains $0.20 \mathrm{mg}$ of vitamin C per gram FW that contributes $13 \%$ of total antioxidant activity in the tuber. Han et al. (2006a) reported that red potato extract prevented liver injury induced by $\mathrm{D}$-galactosamine in rats. They also reported that purple potato flakes have radical scavenging activities inhibiting linoleic acid oxidation and improved antioxidant potential in rats by enhancing hepatic Mn-superoxide dismutase (SOD), $\mathrm{Cu} / \mathrm{Zn}-\mathrm{SOD}$ and glutathione peroxidase (GSH-Px) mRNA expression.

Important food processing operations such as drying, cooking and extrusion may affect the retention of antioxidants in food matrices (Nicoli et al. 1999). However, other than vitamin $\mathrm{C}$, there is limited literature available on the effects of drying/thermal treatments on the antioxidant activities of potatoes.

Blanching and drying are the two most important unit operations in preparing shelf-stable potato flakes as ingredients for the commercial production of a wide range of foods products, including mashed potato and extruded snack foods. The objectives of this study were (1) to quantify the total antioxidant capacity (TAC), total phenolics (TP) and total anthocyanins (TA) in selected potato cultivars; and (2) to study the effect of blanching and consequent drying on the retention of TAC, TP and TA in purple potato cultivars.

\section{MATERIALS AND METHODS}

\section{Raw Materials}

Red (Red Rodeo) potatoes were purchased from an Oregon State potato grower. Yellow (Yukon Gold) and white (Russet) potatoes were purchased from a local store in Pullman, WA. Purple Majesty (CO94165-3P/P) potatoes were purchased in fall of 2007 from Kiska Farms, Burbank, WA and SLV Research Center, Colorado State University. The potatoes were placed in a storage room at $4 \mathrm{C}$ and $80 \%$ relative humidity. Fresh purple potatoes procured from Kiska Farms were used for the production of flakes by refractance window (RW) drying comparison with fresh red, yellow and white potatoes. Purple potatoes procured from Colorado State University were used for the production of drum-dried (DD) and freeze-dried (FD) flakes.

\section{Production of Potato Flakes}

Based on the screening of potato varieties, flakes were prepared only from purple potatoes for further investigation of the effects of blanching and dehydration on TAC, TP and TA. 
Stored purple potatoes were peeled with an abrasive peeler for about $75 \mathrm{~s}$. Peeled potatoes were sliced with a mechanical slicer (Machine type RG-7, Ab Hallade Maskiner, Spanga, Sweden) to $6 \mathrm{~mm}$ thick before blanching in a steam blancher for $8 \mathrm{~min}$ to inactivate polyphenolic oxidase (PPO) similar to the procedures reported for peroxidase inactivation (Reyes and Cisneros-Zevallos 2007). Blanched potato slices were cooled in ice water for $8 \mathrm{~min}$ and then pureed using a mixer (The Hobart Mfg Company, Troy, OH, USA). Additional water was added to the puree to make it of uniform consistency, before placing the puree into the dryers.

Freeze Drying (FD). FD was selected as the reference method for drying. The potato puree was poured on a tray to approximately $2-\mathrm{mm}$ thick, frozen at $-35 \mathrm{C}$ for $1 \mathrm{~h}$, placed into a freeze dryer and dehydrated for $24 \mathrm{~h}$ at $3.33 \mathrm{~Pa}$. The upper plate of the dryer was maintained at $20 \mathrm{C}$ while the condenser temperature was set at $-64 \mathrm{C}$. The dried samples were packed in polyethylene bags, flushed with nitrogen, wrapped in aluminum sheets and stored at $-30 \mathrm{C}$ for further analysis and use.

Drum Drying. A $15.24 \mathrm{~cm} \times 20.32 \mathrm{~cm}$ pilot scale counter rotating twin drum dryer (Blaw Knox Food \& Chemical Equipment Co., Buffalo, NY) was used to dehydrate the puree. Pressurized steam to the drums was maintained at $413 \mathrm{kPa}$ corresponding to a saturation temperature of water at $145 \mathrm{C}$. The surface temperature of the drums was 135$138 \mathrm{C}$. The gap between the drums, rotating at $1.13 \mathrm{rpm}$, was set to $0.3 \mathrm{~mm}$. The dried samples, packed in polyethylene bags, were flushed with nitrogen wrapped in aluminum sheet and stored at $-30 \mathrm{C}$ for further analysis and use.

RW Drying. A pilot scale RW dryer of an effective length and width of $1.83 \times 0.60 \mathrm{~m}$ developed by MCD Technologies, Inc. (Tacoma, WA) was used to dehydrate the potato puree. The dryer consisted of a plastic conveyer belt rotating at a speed of $1.04 \mathrm{~m} / \mathrm{min}$ in contact with hot water circulated at 95C. Potato puree prepared using a Hobert mixer (Hobert Corporation, Troy, $\mathrm{OH}$ ) was poured on a roller feeder, which deposited a thin layer $(1 \mathrm{~mm})$ of puree on the conveyor belt. The conveyer belt transported the puree over a heating section for drying, then through a cooling section, before the dried flakes were scraped from the end. Average air velocity over the conveyer was $0.7 \mathrm{~m} / \mathrm{s}$ and residence time of the puree on the belt was $1 \mathrm{~min} 55 \mathrm{sec}$. Dried flakes were packed in polyethylene bags, flushed with nitrogen, kept in aluminum bags, heat sealed and stored at $-30 \mathrm{C}$ for further analysis and use.

\section{Chemical Analysis}

The moisture content of the raw cultivars and dried flakes was determined by the vacuum oven method (AOAC 1995).
Folin-Ciocalteu (FC) reagent, potassium chloride, sodium acetate, Trolox (6-Hydroxy-2,5,7,8-tetramethylchromane-2carboxylic acid), DPPH (2, 2-diphenyl-1-picrylhydrazyl) and gallic acid were purchased from Sigma-Aldrich (St. Louis, $\mathrm{MO})$. Laboratory grade methanol and ethanol were used in extraction and preparation of samples.

Total Antioxidant Capacity. Total antioxidant capacities (TACs) of raw potatoes were quantified using the DPPH (2, 2-diphenyl-1-picrylhydrazyl) assay (Brandwilliams et al. 1995). DPPH, a stable radical deep purple in color, is reduced in the presence of antioxidants decolorizing the solution. The loss of color results in a decrease in the absorbance intensity, thus providing a basis for measurement of antioxidant activities in the extracts. Thirty grams of potatoes peeled by an abrasive peeler (Model 15A, MJM Mfg Co., Culver City, CA) were chopped and homogenized with $100 \mathrm{~mL}$ of HPLC grade methanol to a uniform consistency by a homogenizer (Omni Mix Homogenizer, Omni International, Waterbury, CT). The samples were centrifuged (Beckman J2-HS Centrifuge, Beckman Coulter Inc., Palo Alto, CA) at $30,000 \times \mathrm{g}$ at $4 \mathrm{C}$ for $20 \mathrm{~min}$ and the supernatants stored at $-20 \mathrm{C}$ for further analysis. A $6 \times 10^{-5} \mathrm{M} \mathrm{DPPH}$ solution was prepared in methanol and stored at $-20 \mathrm{C}$ for analysis.

Stored supernatants were diluted twofold with methanol and $0.05 \mathrm{~mL}$ of diluted supernatants was added to $1.95 \mathrm{~mL}$ of DPPH solution in a cuvette. Aliquots in cuvettes were covered with Parafilm and vortexed with a mini vortexer (MV1, Wilmington, NC) before taking absorbance readings at selected times with an Ultraspec 4,000 UV/visible spectrophotometer (Pharmacia Biotech, Cambridge, UK) until absorbance values reached a plateau. The spectrophotometer was blanked with methanol. DPPH without sample was taken as control. For each sample measured, the percentage of DPPH remaining was calculated as follows:

$$
(D P P H)_{\text {remaining }}=\frac{D P P H_{\text {absorbance } @ T=t}}{D P P H_{\text {absorbance } @ T=0}} \times 100
$$

where $D P P H_{\text {absorbance } @=t}$ is the absorbance of DPPH at time $\mathrm{t}$ min and $D P P H_{\text {absorbance@T=0 }}$ is the absorbance of DPPH at zero min. Trolox (6-Hydroxy-2,5,7,8-tetramethylchromane-2carboxylic acid) was used as a standard. The absorbance readings at $2 \mathrm{~h}$ after which there was no additional change were used to calculate TAC from the trolox standard curve. All the values of TAC were expressed as micrograms of trolox equivalent per gram of dry weight sample $(\mu \mathrm{g} \mathrm{TE} / \mathrm{g} \mathrm{DW}) \pm \mathrm{SD}$ for three replications.

Total antioxidant capacity in purple dried flakes extracts were prepared from $10 \mathrm{~g}$ of dried flakes initially rehydrated with $40-\mathrm{mL}$ water and blended with $40-\mathrm{mL}$ HPLC grade methanol. The final volume of the mixture was made to 
$100 \mathrm{~mL}$ with aqueous methanol $(50: 50 \mathrm{v} / \mathrm{v})$. The mixture was centrifuged at $30,000 \times \mathrm{g}$ at $4 \mathrm{C}$ for $20 \mathrm{~min}$ and supernatants stored at $-20 \mathrm{C}$ for further analysis.

Total Phenolics. TP were determined using extracts prepared for TAC using FC colorimetric method as described by Swain and Hillis (1959) and Singleton and Rossi (1965). Supernatants were diluted fourfold with methanol. To $0.5 \mathrm{~mL}$ aliquots $8 \mathrm{~mL}$ of deionized water was added followed by $0.5 \mathrm{~mL}$ of $0.25 \mathrm{~N}$ FC reagent, and the samples were vortexed, kept for $3 \mathrm{~min}$ and $1 \mathrm{~mL}$ of $1 \mathrm{~N}$ sodium carbonate was added and the mixture vortexed. The samples were kept at room temperature for $2 \mathrm{~h}$ before taking readings at $725 \mathrm{~nm}$ in the UV Spectrophotometer. One-half milliliter methanol was treated in the same way as the diluted samples and used as a blank. The TP analyses were triplicated and means $( \pm \mathrm{SD})$ reported as micrograms gallic acid equivalent per gram of dry weight sample ( $\mu \mathrm{g}$ GAE/g DW) from a standard curve developed for gallic acid.

Total Anthocyanins. Potatoes were extracted for anthocyanin analysis using the procedure of Fuleki and Francis (1968) with modifications. Raw stored potatoes were peeled with an abrasive peeler for $75 \mathrm{sec}$ and the surface moisture removed with tissue paper. Peeled potatoes were chopped manually to small pieces and $30 \mathrm{~g}$ homogenized with $150 \mathrm{~mL}$ of the acidified ethanol (95\% ethanol/1.5 N HCl, 85:15 v/v) to a uniform consistency. The samples were kept for $10 \mathrm{~min}$ at room temperature and extracts were decanted into a beaker. The residues were washed with $100 \mathrm{~mL}$ of the acidified ethanol and extracts from first and second washings and residues were mixed, covered with Parafilm, and stored for $90 \mathrm{~min}$ at $4 \mathrm{C}$. The samples were centrifuged at $23,000 \times \mathrm{g}$ at $4 \mathrm{C}$ for $15 \mathrm{~min}$ and supernatants stored at $-20 \mathrm{C}$ for further analysis.

The quantification of anthocyanins was carried out using the $\mathrm{pH}$ differential method described by Giusti and Wrolstad (2001). Diluted aliquots containing $0.2 \mathrm{~mL}$ of anthocyanins extract and $1.8 \mathrm{~mL}$ buffer were prepared in $2 \mathrm{~mL}$ cuvettes with $\mathrm{KCl}$ buffer ( $\mathrm{pH} 1.0)$ or sodium acetate buffer $(\mathrm{pH} 4.5)$, respectively. The diluted aliquots were vortexed with a mini vortexer and equilibrated for $15 \mathrm{~min}$ at room temperature. Absorbance readings were taken at maximum wavelength $(\lambda$-max $)$ of $535 \mathrm{~nm}$ for purple cultivars, $515 \mathrm{~nm}$ for red and yellow cultivars and $700 \mathrm{~nm}$ for correcting for turbidity (Reyes and Cisneros-Zevallos 2003) in a UV/visible spectrophotometer, previously blanked with distilled water. Total anthocyanins in purple cultivars were quantified by considering malvidin-3glucoside (Lewis et al. 1998; Jansen and Flamme 2006; Han et al. 2006b) as the major anthocyanin with $\mathrm{MW}=718.5 \mathrm{~g} /$ mol and molar extinction coefficient of $30,200 \mathrm{~L} / \mathrm{cm}$ per mol. Pelargonidin-3-glucosides having e $=27,300 \mathrm{~L} / \mathrm{cm}$ per $\mathrm{mol}$ and $\mathrm{MW}=486.5 \mathrm{~g} / \mathrm{mol}$ (Fuleki and Francis 1968) were considered as the major anthocyanins in red cultivars, whereas, cyanidin-3-glucosides were considered as the major anthocyanin in yellow cultivars. Total anthocyanins content in potato extracts were calculated according to the formula (Giusti and Wrolstad 2001):

$$
C(m g / l)=\frac{A * M W * D F}{e * d}
$$

where $\mathrm{A}=$ absorbance of the sample, $\mathrm{MW}=$ molecular weight of major anthocyanin, $\mathrm{DF}=$ dilution factor, $\mathrm{e}=$ molar extinction coefficient of major anthocyanin and $d=$ path length of the cuvette $(1 \mathrm{~cm})$. The absorbances of the samples were calculated as $A=\left(A_{\lambda \max }-A_{700}\right)_{p H 1.0}-\left(A_{\lambda \max }-A_{700}\right)_{p H 4.5}$. Total anthocyanins were expressed as mg of major anthocyanin per gram of DW sample mean \pm SD for three replications.

For TA determination in dehydrated purple potato flakes, $5 \mathrm{~g}$ of flakes were rehydrated with $40-\mathrm{mL}$ water and blended with $40 \mathrm{~mL}$ of acidified ethanol (95\% ethanol/1.5 N HCl $[85: 15 \mathrm{v} / \mathrm{v}])$. The samples were thoroughly mixed by stirring manually and decanted to a separate beaker. The residues were washed again, the extracts decanted and mixed with the first decanted extracts. The total extracts were made to a total volume of $100 \mathrm{~mL}$ with 50:50 (v/v) water: acidified ethanol and centrifuged at $23,000 \times \mathrm{g}$ at $4 \mathrm{C}$ for $15 \mathrm{~min}$. The supernatants were stored at $-20 \mathrm{C}$ for further analysis.

\section{Color Determination}

The color of raw cultivars and dehydrated flakes were determined using a color meter (Minolta Chroma CR200, Minolta Co., Osaka, Japan) with $L^{\star} a^{\star} b^{\star}$ values depicting brightness, greenness/redness and blue/yellowness, respectively. The color meter was calibrated with standards provided by the manufacturer. The hue angle $h^{\circ}\left[h^{\circ}=\arctan \left(b^{\star} / a^{\star}\right)\right]$ and Chromaticity $C^{\star}\left[C^{\star}=\left(a^{\star 2}+b^{\star 2}\right)^{1 / 2}\right]$ were computed from $a^{*}$ and $b^{*}$. Color differences between dehydrated samples and raw samples were expressed as $\Delta \mathrm{E}^{*}$ where $\Delta E^{\star}=$ $\left[\left(\Delta L^{\star}\right)^{2}+\left(\Delta a^{*}\right)^{2}+\left(\Delta b^{*}\right)^{2}\right]^{1 / 2}$. Peeled potatoes were sliced to measure the color attributes in raw cultivars. Dehydrated flakes were ground with mortar and pestle and covered with ultra thin transparent polyethylene sheet before measurements were taken.

\section{Statistical Analysis}

Color, TAC, TP and TA data for raw and dehydrated potato samples were analyzed with SAS software (version 9.1, SAS Institute Inc., Cary, NC). Significant differences among treatments were determined using analysis of variance followed by Tukey's pair-wise comparisons at 95\% confidence level 
TABLE 1. TOTAL ANTIOXIDANT CAPACITY, TOTAL PHENOLICS CONTENT AND TOTAL ANTHOCYANINS OF SELECTED RAW POTATO CULTIVARS EXPRESSED AS QUANTITY PER GRAM OF DRY WEIGHT SAMPLE $(N=3)$

\begin{tabular}{llllc}
\hline Cultivars & $\begin{array}{l}\text { Dry matter } \\
(\mathrm{g} / \mathrm{g} \text { of sample })\end{array}$ & $\begin{array}{l}\text { Total antioxidant capacity } \\
(\mu \mathrm{g} \text { Trolox/g DW) }\end{array}$ & $\begin{array}{l}\text { Total phenolics } \\
(\mu \mathrm{g} \text { GAE } / \mathrm{g} \mathrm{DW})\end{array}$ & $\begin{array}{l}\text { Total anthocyanins } \\
(\mathrm{mg} / \mathrm{g} \text { DW })\end{array}$ \\
\hline Purple & 0.23 & $9,605 \pm 404^{\mathrm{a}}$ & $3,347 \pm 198^{\mathrm{a}}$ & $1.08 \pm 0.09^{\mathrm{a}}$ \\
Red & 0.24 & $2,542 \pm 120^{\mathrm{b}}$ & $1,457 \pm 240^{\mathrm{c}}$ & $0.014 \pm 0.004^{\mathrm{b}}$ \\
Yellow & 0.23 & $2,403 \pm 90^{\mathrm{b}}$ & $1,425 \pm 200^{\mathrm{c}}$ & $0.014 \pm 0.004^{\mathrm{b}}$ \\
White & 0.23 & $2,518 \pm 471^{\mathrm{b}}$ & $2,096 \pm 482^{\mathrm{b}}$ & - \\
\hline
\end{tabular}

Significant differences within the values in the same column are indicated by different superscript letters $(P<0.05)$.
$(P \leq 0.05)$. Triplicate $(n=3)$ data obtained from the different analyses were reported as arithmetic mean and standard deviation.

\section{RESULTS AND DISCUSSION}

\section{Moisture Content, TAC, TP and TA in Raw Potatoes}

The moisture contents of the selected raw potato tubers were $77 \%$ (wet basis). There was no significant difference $(P<0.05)$ in the moisture contents in the raw cultivars. Also, no significant differences $(P<0.05)$ were observed in TAC, $\mathrm{TP}$ and TA contents between purple potatoes procured from Washington and Colorado State locations. However, it was observed that purple potatoes contain more TAC, TP and TA than the red, yellow and white potato cultivars (Table 1). The TAC among the different sample cultivars ranged from 2,403 to $9,605 \mu \mathrm{g}$ TE/g DW. Samples from purple cultivar without skin had the highest TAC with 9,605 $\mu \mathrm{g}$ TE/g DW. White, red and yellow had similar TAC of $\sim 2,400-2,500 \mu \mathrm{g}$ TE/g DW. Reddivari et al. (2007) reported that the antioxidant activity of whole potato cultivars varied from 157 to $832 \mu \mathrm{g}$ TE/g of FW using DPPH assay and 810 to $1,622 \mu \mathrm{g}$ TE/g of FW using ABTS assay. A higher antioxidant capacity of whole purple and red-fleshed potatoes ranging from 513 to $1,426 \mu \mathrm{g}$ TE/g of FW was also reported (Reyes et al. 2005).

The amount of TP varied from 1,425 to $3,347 \mu \mathrm{g}$ GAE/g DW among the cultivars under study. The TP content in the flesh of purple potato cultivar was significantly higher (3,347 $\mu \mathrm{g}$ GAE/g DW) than those obtained in white $(2,096 \mu \mathrm{g}$ GAE/g DW), red (1,457 $\mu \mathrm{g}$ GAE/g DW) and yellow $(1,425 \mu \mathrm{g}$ GAE/g DW) cultivars. Andre et al. (2007) have previously reported TP content in white and colored potato cultivars in the range of 2,360 to $12,370 \mu \mathrm{g}$ GAE/g FW.

Total anthocyanins content in the flesh of purple potato cultivars (from Washington State) was $1.08 \mathrm{mg} \mathrm{MV-3-GLU/g}$ DW, while the red and yellow cultivars contained smaller amount of TA (Table 1). Similarly, Reyes et al. (2005) reported that the TA content in the flesh of purple potato ranged from 0.11 to $1.74 \mathrm{mg}$ CY-3-GLU/g FW and from 0.21 to $0.55 \mathrm{mg}$ CY-3-GLU/g FW in the flesh of red potatoes. Dark purple black tubers having 2 to 5 mg of MV-3-GLU/g FW and red-fleshed potato cultivars with 0.02 to $0.40 \mathrm{mg}$ pelargonidin-3-glucoside/g FW was reported by RodriguezSaona et al. (1998). The differences in TAC, TP and TA content for the studied cultivars could be because of environmental conditions, growing location, harvesting time, maturity, sample preparation and extraction methods used for their evaluation.

\section{Effects of Blanching on TAC, TP and TA}

Preliminary RW drying of potato puree from purple cultivars without blanching caused complete loss of purple color in the flakes (Fig. 2). This loss in color may be because of the PPO activity (Reyes and Cisneros-Zevallos 2007). Color loss in purple potato puree was observed, once the tubers were cut into slices and ground. The color of the puree turned brown and became colorless after RW dehydration. Therefore, in an effort to prevent enzymatic browning to occur, we steamblanched the purple potato slices for $8 \mathrm{~min}$ prior to processing them into puree for subsequent drying.

Purple potato product obtained from steam-blanched puree, prior to drum drying and FD, retained about $90 \%$ of TA compared with raw puree (Table 2). Reyes and CisnerosZevallos (2007) reported that red and purple fleshed potatoes of $\sim 5-\mathrm{mm}$ thickness steam-blanched for $3 \mathrm{~min}$ had $98 \%$ reduction in peroxidase activity. The retention of $23 \%$ of TA in blueberries was reported by Rossi et al. (2003) after blanching, compared with $12 \%$ without blanching, before processing into juice. Using a reverse-phase HPLC separation system for separating individual anthocyanins, Rossi et al. (2003) observed that the recovery of anthocyanin from blueberries after blanching was maximum for delphinidin-3-arabinoside $(1,936 \%)$ followed by petunidin $(586 \%)$ and cyanidin (191\%) glucosides, whereas malvidin glucosides showed the least recovery $(143 \%)$. The investigators also reported that the minor recovery of malvidin glucosides could be because of the structure of the anthocyanin having a single hydroxyl group on its phenolic ring that was least affected by PPO compared with the other anthocyanins. In the present study, puree from purple potatoes without blanching prior to RW drying did not retain any color. The complete loss of color in the puree could be because of the activity of PPO. On the other hand, the retention of anthocyanins and color in the potato 


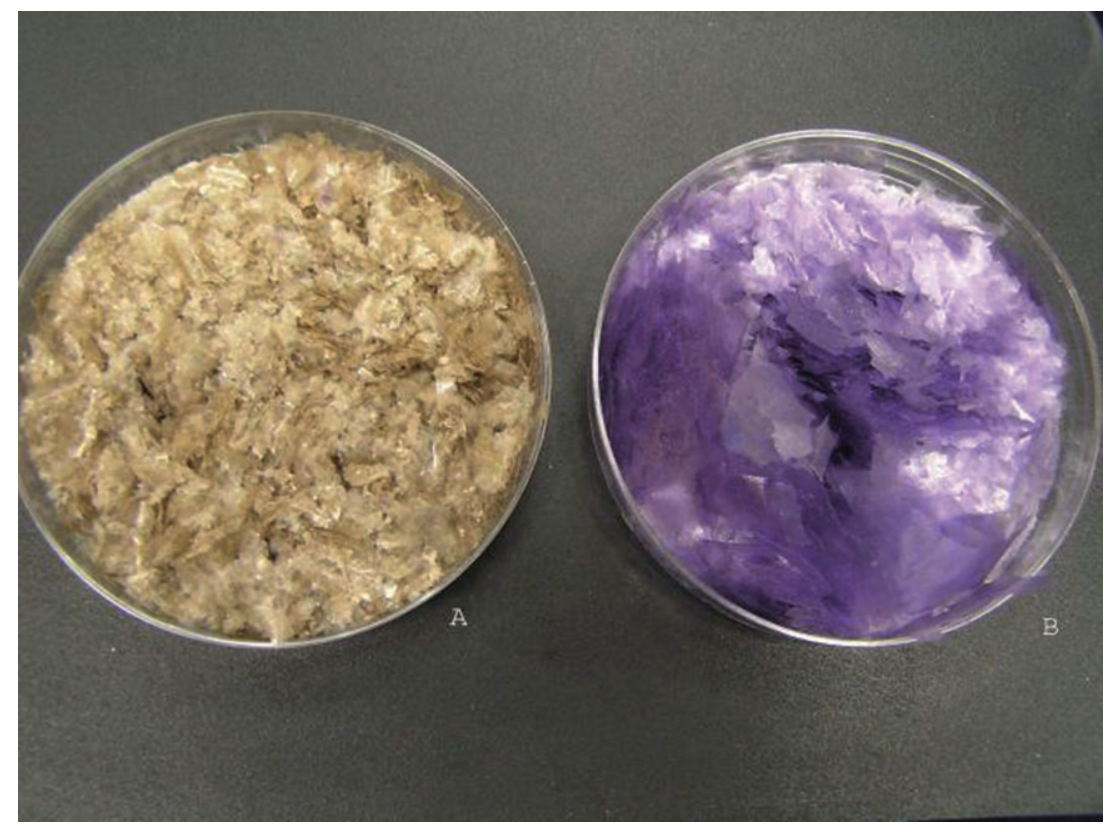

FIG. 2. COLOR OF POTATO FLAKES; (A) WITHOUT BLANCHING; (B) WITH BLANCHING puree after blanching could be because of the inactivation of $\mathrm{PPO}$ and subsequent reduction in enzymatic anthocyanin degradation.

The blanching of sliced potatoes also showed a significant increase $(P<0.05)$ in TAC $(75 \%)$ and TP $(108 \%)$ in the puree compared with unblanched puree (Table 2). Wang (2002) reported an increase in total antioxidant activities of 7 and $26 \%$ after water and microwave blanching of asparagus spears, respectively. The increases in the TAC and TP content after blanching could be because of the greater extraction yield by opening up the cell and increasing cell permeability to bound phenolics (Kalt et al. 2000). The release of lycopene in tomatoes (Dewanto et al. 2002a), phenolics in apple peels (Wolfe and Liu 2003) and ferulic acid in corn (Dewanto et al. 2002b) were also reported during heat processing. These reports agreed with the results of the present study with regard to the beneficial effect of blanching of retention of TA activity in the final product.

\section{TAC, TP and TA in Dehydrated Potato Flakes}

All of the dehydrated flakes had similar moisture contents: $6.0 \%$ (wet basis) for FD flakes; 5.9\% (wet basis) for RW-dried flakes; and 5.2\% (wet basis) for DD flakes. There was no significant difference $(P<0.05)$ among the moisture contents of the flakes. The TAC content in FD, RW-dried and DD flakes were $8,151,7,331$ and 7,021 $\mu \mathrm{g}$ TE/g DW, respectively. There was no significant change $(P<0.05)$ in TAC content of dry flakes compared with raw sample for all drying methods used in this study. The TP content in flakes prepared by drum drying $(4,021 \mu \mathrm{g}$ GAE/g DW) was not significantly different $(P<0.05)$ from freeze drying $(3,950 \mu \mathrm{g}$ GAE/g DW $)$.

\begin{tabular}{|c|c|c|c|}
\hline & TAC ( $\mu \mathrm{g}$ Trolox/g DW) & $\mathrm{TP}(\mu \mathrm{g}$ GAE /g DW) & $\mathrm{TA}(\mathrm{mg} / \mathrm{g} \mathrm{DW})$ \\
\hline Raw (CO) & $8,787 \pm 630^{b}$ & $3,835 \pm 296^{c}$ & $1.74 \pm 0.16^{a}$ \\
\hline Blanched & $15,358 \pm 2,948^{a}$ & $7,993 \pm 488^{a}$ & $1.58 \pm 0.08^{a}$ \\
\hline Drum dried & $7,021 \pm 911^{b}$ & $4,021 \pm 136^{c}$ & $1.03 \pm 0.02^{b}$ \\
\hline Freeze dried & $8,151 \pm 37^{b}$ & $3,950 \pm 124$ & $0.96 \pm 0.17^{b}$ \\
\hline $\operatorname{Raw}^{*}(\mathrm{WA})$ & $9,605 \pm 405^{b *}$ & $3,347 \pm 198^{c *}$ & $1.08 \pm 0.09^{\mathrm{a} *}$ \\
\hline Refractance window dried & $7,331 \pm 246^{b *}$ & $4,680 \pm 120^{b *}$ & $0.83 \pm 0.01^{b *}$ \\
\hline
\end{tabular}

TABLE 2. TOTAL ANTIOXIDANT CAPACITY (TAC), TOTAL PHENOLICS (TP) AND TOTAL ANTHOCYANINS (TA) OF RAW, BLANCHED AND DRIED POTATO FLAKES FROM PURPLE CULTIVARS

* Cultivar from a different location and storage time was used for refractance window drying.

TAC, TP and TA of blanched and dried flakes were compared with raw cultivars and expressed in quantity per gram of dry sample $(n=3)$.

Significant differences within the values in the same column are indicated by different superscript letters $(P<0.05)$

CO, Colorado; WA, Washington. 
However, there was a significant increase $(P<0.05)$ of these components observed in the flakes prepared by RW drying (4,680 $\mu \mathrm{g}$ GAE/g DW). Flakes prepared by drum drying, FD and RW drying had TA contents of 1.03, 0.96 and $0.83 \mathrm{mg}$ MV-3-GLY/g DW, respectively. There were significant losses of $23-45 \%$ TA contents observed in potato flakes compared with raw samples (Table 2).

Many researchers have reported that processing causes major losses in the antioxidant concentration of fruits and vegetables, mainly because of enzymatic and chemical oxidation of antioxidants. However, most of the literature focuses on the degradation of vitamin $\mathrm{C}$ in fruits and vegetables during blanching, dehydration or heating (Van den broeck et al. 1998), and very few data are available on polyphenols and other compounds that contribute to the antioxidant activities in fruits and vegetables. In the present study, no significant change $(P<0.05)$ in TAC was observed in the dehydrated potato flakes compared with raw samples, regardless of the drying method used. Blessington et al. (2007) reported an increase in the content of carotenoids and DPPH antioxidant activities during frying and microwave drying of potatoes. Dewanto et al. (2002b) also reported an increase of $44 \%$ in TA activities in heat processed sweet corn (115C for $25 \mathrm{~min}$ ) despite a $25 \%$ loss in vitamin C. There was no significant change observed in antioxidant activities during FD of apple peels (Wolfe and Liu 2003), baking (at 177C for $20 \mathrm{~min}$ ) of wheat bran (Singh et al. 2007) and canning of chick pea proteins processed at $121 \mathrm{C}$ for $20 \mathrm{~min}$ (Arcan and Yemenicioglu 2007). The retention of antioxidant activities in processed fruits and vegetables have been attributed to protein hydrolysis, Maillard reaction and fermentation process (Nicoli et al. 1999). In the present study, the observed retention of TAC might be because of a combination of the natural phytochemicals present in the potato and Maillard reaction products (MRPs) that contribute to the overall antioxidant activities of the potato flake. Reports by Nicoli et al. (1999) also support that Maillard products formed during processing contributed to the formation of antioxidants in roasted coffee, enhancing the total antioxidant capacity of the product.

Phenolics were also retained after the dehydration of purple potatoes by DD and FD, and a significant increase was observed because of RW drying when compared with raw tubers. There is limited literature available to compare the effect of drying and other thermal treatments on total phenolics in potatoes. In a study on antioxidant values of phenolic acids in potatoes, Friedman (1997) reported complete loss of phenolic acids by cooking. In contrast, Blessington (2005) observed higher TP content in potato processed by microwaving, frying and baking than boiling. Wolfe and Liu (2003) reported a significant increase of phenolic contents in FD apple peels compared with the fresh peels. The retention and increase in TP during blanching and dehydration may be

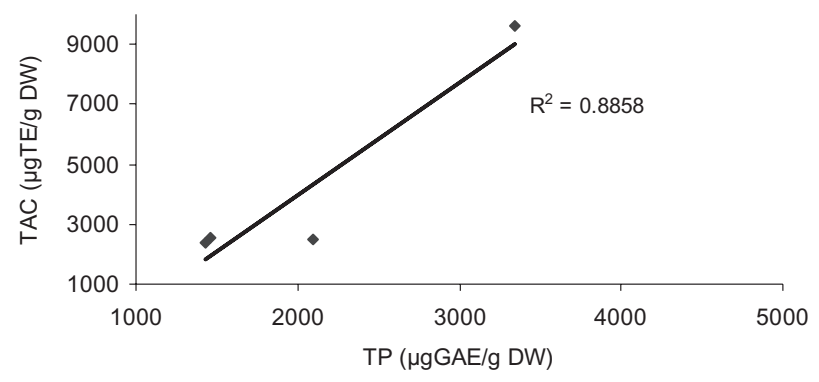

FIG. 3. CORRELATION BETWEEN TOTAL ANTIOXIDANT CAPACITY (TAC) AND TOTAL PHENOLICS (TP) IN RAW COLORED (PURPLE, RED, YELLOW) AND WHITE POTATO CULTIVARS

attributed to the opening of the cell matrix and release of bound phenolics.

Blanching followed by drying of peeled purple potatoes reduced the content of total anthocyanins by $20-40 \%$ in the flakes. Singh et al. (2007) reported complete loss of anthocyanins in purple wheat bran during baking. Other researchers reported either increase or no change in TA content during drying of carrots (Uyan et al. 2004). It has been well studied that temperature, $\mathrm{pH}$, oxygen and light affect the stability of anthocyanins. Reyes and Cisneros-Zevallos (2007) reported a first-order thermal degradation of anthocyanin extracts from colored potatoes at different $\mathrm{pH}$. Anthocyanins lose the glucosides by deglycosylation to form chalcones that further degrades to acids and aldehydes (Sadilova et al. 2006).

\section{Correlation Between TP and TAC}

A small negative linear correlation was found between TP and TAC $\left(r^{2}=-0.119\right)$ in dried potato flakes, indicating little relationship between these parameters. Therefore, these data do not suggest that TP are primarily responsible for the total antioxidant capacity in potato flakes dehydrated by DD, FD and RW. However, in colored (purple, red, yellow) and white raw potato cultivars, a large positive correlation between TP and TAC $\left(r^{2}=0.8858\right)$ was observed (Fig. 3). Reyes and Cisneros-Zevallos (2003) reported that wounding-induced phenolic compounds in potatoes were positively correlated to antioxidant activities. Many researchers also reported a high positive correlation between antioxidant capacity and total phenolics content (in terms of chlorogenic acid equivalent) in whole raw potatoes (Reyes et al. 2005; Reddivari et al. 2007). In contrast, Hale (2003) observed that the concentration of phenolic acid contributed very little to antioxidant activities in raw potatoes $\left(r^{2}=0.18\right)$. There has been little information reported on the correlation between TP and TAC in processed potatoes. The observed difference in correlation between raw cultivars and dehydrated potato flakes suggests that MRPs formed during processing may contribute significantly to the 
TABLE 3. COLOR ATTRIBUTES OF RAW POTATO CULTIVARS $(n=3)$

\begin{tabular}{llcr}
\hline Cultivars & Lightness $\left(L^{\star}\right)$ & Chromaticity $\left(C^{\star}\right)$ & Hue angle $\left(h^{\circ}\right)$ \\
\hline Purple & $19.3 \pm 2.4^{\mathrm{c}}$ & $8.2 \pm 0.5^{\mathrm{c}}$ & $320.2 \pm 0.9^{\mathrm{a}}$ \\
Red & $65.6 \pm 2.1^{\mathrm{b}}$ & $24.3 \pm 1.7^{\mathrm{a}}$ & $271.7 \pm 0.2^{\mathrm{b}}$ \\
Yellow & $63.8 \pm 2.2^{\mathrm{b}}$ & $25.0 \pm 0.5^{\mathrm{a}}$ & $89.6 \pm 0.3^{\mathrm{c}}$ \\
White & $69.4 \pm 1.6^{\mathrm{a}}$ & $15.6 \pm 0.6^{\mathrm{b}}$ & $271.6 \pm 0.1^{\mathrm{b}}$ \\
\hline
\end{tabular}

Significant differences within the values in the same column are indicated by different superscript letters $(P<0.05)$.

total antioxidant capacity in the extracts from dehydrated flakes.

\section{Color in Raw Cultivars and Dehydrated Flakes}

Visual color attributes of the raw cultivars expressed in terms of lightness, hue and chromaticity are shown in Table 3. Lightness $\left(L^{*}\right)$ of white potato was highest $(P<0.05)$ among the cultivars tested and purple potato had the smallest $L^{*}$ value $(P<0.05)$, while the red and yellow cultivars had similar $L^{\star}$ values. Chromaticity values followed the same pattern observed for lightness, that is, white potato showed the highest and purple potato the smallest color saturation. Red and yellow cultivars were not different in lightness or chromaticity, but were significantly different in hue angle $(P<0.05)$. The purple potato cultivar was significantly different in all color attributes from other cultivars.

Upon dehydration of white and colored potato samples, a significant increase in lightness was observed for all samples under different dehydration processes (Table 4). FD and RW dried flakes had similar $L^{*}$ values and were significantly brighter $(P<0.05)$ than DD flakes. Similar results were reported on heating of black carrot, strawberry and elderberry extracts (Sadilova et al. 2006). The color purity of the FD flakes expressed as chroma was similar to the raw potatoes whereas significantly higher values $(P<0.05)$ were observed for DD and RW dried flakes. The higher saturation of color observed in the DD and RW dried samples could be because of the exposure of potato puree to air and light for shorter times during these drying processes than sample processed by FD technology. The residence time of potato puree on DD and RW drier was around 53 and $115 \mathrm{sec}$, respectively, whereas, puree samples were kept for $24 \mathrm{~h}$ in the freeze dryer, which provided higher exposure time under this drying condition. Similarly, Sadilova et al. (2006) observed a significant decrease in chroma of black carrot, strawberry and elderberry extracts after heating $7 \mathrm{~h}$, depicting dullness/less saturated color in the samples.

Hue values of all the potato flakes dehydrated under the different drying process were significantly different $(P<0.05)$ from each other (Table 4). Flakes from the DD were higher in hue value, depicting more reddish than RW and FD flakes. Also, the color of raw purple cultivars were shifted toward red with higher hue value than the dehydrated flakes. Reyes and Cisneros-Zevallos (2007) reported an increase in hue-value in red and purple-fleshed potato extracts when exposed to 98C. On the other hand, Sadilova et al. (2006) reported an initial decrease in hue-values after $3 \mathrm{~h}$ of heating of black carrot, strawberry and elderberry extracts at $98 \mathrm{C}$, followed by an increase in the hue value more than that of unheated extracts. The overall color attributes of the dehydrated potato flakes were determined by color differences compared with the raw potato sample. Lesser differences in color indicate better stability of pigments in the samples. Color differences $(\Delta \mathrm{E})$ in DD flakes were significantly less $(P<0.05)$ than those obtained from FD and RW dried flakes, indicating more preservation of the original color in flakes dried by DD. Despite the observed variation in color difference between DD and FD flakes, the concentration of anthocyanins in those flakes was not significantly different $(P<0.05)$.

\section{CONCLUSION}

The evaluation of antioxidant compounds present in purple, red, yellow and white potatoes showed that purple potato cultivar contains significantly more total antioxidants, TP and TA than other potato cultivars. Dry flakes prepared from steam-blanched purple potatoes retained the purple color. However, those flakes obtained from purple potatoes without previous blanching lost the purple color. Therefore, blanching demonstrated to be an important operation for treating purple potatoes before dehydration. Different drying technologies (drum drying, FD and RW drying) used to prepare dehydrated purple potato flakes did not significantly change $(P<0.05)$ total antioxidant content. Similar results were also observed in TP content in the dehydrated purple potato flakes

\begin{tabular}{llclc}
\hline Cultivars & Lightness $\left(L^{*}\right)$ & Chromaticity $\left(C^{\star}\right)$ & Hue angle $\left(h^{\circ}\right)$ & Color difference $\left(\Delta \mathrm{E}^{*}\right)$ \\
\hline Raw & $19.3 \pm 2.4^{\mathrm{c}}$ & $8.2 \pm 0.5^{\mathrm{b}}$ & $320.2 \pm 0.9^{\mathrm{a}}$ & 0.0 \\
Freeze dried & $54.0 \pm 2 .^{\mathrm{a}}$ & $7.2 \pm 0.6^{\mathrm{b}}$ & $270.5 \pm 0.1^{\mathrm{d}}$ & $35.28 \pm 0.99^{\mathrm{a}}$ \\
Drum dried & $45.7 \pm 1.2^{\mathrm{b}}$ & $12.2 \pm 1.0^{\mathrm{a}}$ & $296.2 \pm 0.3^{\mathrm{b}}$ & $27.04 \pm 3.37^{\mathrm{b}}$ \\
RW dried & $55.3 \pm 0.9^{\mathrm{a}}$ & $12.2 \pm 0.7^{\mathrm{a}}$ & $293.6 \pm 0.2^{\mathrm{c}}$ & $36.49 \pm 2.01^{\mathrm{a}}$
\end{tabular}

TABLE 4. COLOR ATTRIBUTES OF PURPLE DEHYDRATED FLAKES $(n=3)$

Significant differences within the values in the same column are indicated by different superscript letters $(P<0.05)$. 
prepared by FD and drum drying. Conversely, a significantly higher $(P<0.05)$ TP content was obtained by RW drying in the potato flakes. Losses of $23-45 \%$ in total antioxidant content were observed in the dehydrated potato flakes processed under all drying methods. The results suggest that processing colored potatoes into value-added antioxidant-rich ingredient may contribute to the production of healthy snacks and other foods. A detailed kinetic study of antioxidants during processing of potatoes is needed to better understand the behavior of antioxidants in food systems.

\section{ACKNOWLEDGMENTS}

We acknowledge the financial support from Washington State Potato Commission, Moses Lake, WA, USA and partial support from Washington State University Agricultural Research Center.

\section{REFERENCES}

ANDRE, C.M., GHISLAIN, M., BERTIN, P., OUFIR, M., HERRERA, M.D., HOFFMANN, L., HAUSMAN, J.F., LARONDELLE, Y. and EVERS, D. 2007. Andean potato cultivars (Solanum tuberosum L.) as a source of antioxidant and mineral micronutrients. J. Agric. Food Chem. 55, 366-378.

AOAC 1995. Official Methods of Analysis (16th. Ed.), Association of Official Analytical Chemistry, Washington, DC.

ARCAN, I. and YEMENICIOGLU, A. 2007. Antioxidant activity of protein extracts from heat-treated or thermally processed chickpeas and white beans. Food Chem. 103, 301-312.

BLESSINGTON, T. 2005. The Effects of Cooking, Storage and Ionizing Irradiation on Carotenoids, Antioxidant Activity and Phenolics in Potato, Texas A\&M, College Station, Texas, TX. BLESSINGTON, A., MILLER, J.C., NZARAMBA, M.N., HALE, A.L., REDIVARI, L., SCHEURING, D.C. and HALLMAN, G.J. 2007. The effects of low-dose gamma irradiation and storage time on carotenoids, antioxidant activity, and phenolics in the potato cultivar Atlantic. Am. J. Potato Res. 84, 125-131.

BRANDWILLIAMS, W., CUVELIER, M.E. and BERSET, C. 1995. Use of a free-radical method to evaluate antioxidant activity. Lebensm. Wiss. Technol. 28, 25-30.

BROWN, C.R. 2005. Antioxidants in potato. Am. J. Potato Res. 82, 163-172.

BROWN, C.R., WROLSTAD, R., DURST, R., YANG, C.P. and CLEVIDENCE, B. 2003. Breeding studies in potatoes containing high concentrations of anthocyanins. Am. J. Potato Res. 80, 241-249.

CEVALLOS-CASALS, B.A. and CISNEROS-ZEVALLOS, L. 2003. Stoichiometric and kinetic studies of phenolic antioxidants from Andean purple corn and red-fleshed sweetpotato. J. Agric. Food Chem. 51, 3313-3319.

DEWANTO, V., WU, X.Z., ADOM, K.K. and LIU, R.H. 2002a. Thermal processing enhances the nutritional value of tomatoes by increasing total antioxidant activity. J. Agric. Food Chem. 50, 3010-3014.

DEWANTO, V., WU, X.Z. and LIU, R.H. 2002b. Processed sweet corn has higher antioxidant activity. J. Agric. Food Chem. 50, 4959-4964.

FRIEDMAN, M. 1997. Chemistry, biochemistry, and dietary role of potato polyphenols. A review. J. Agric. Food Chem. 45, 1523-1540.

FULEKI, T. and FRANCIS, F.J. 1968. Quantitative methods for anthocyanins-I. Extraction and determination of total anthocyanin in cranberries. J. Food Sci. 33, 72-77.

GIUSTI, M.M. and WROLSTAD, R. 2001. Characterization and measurement of anthocyanin by UV-visible spectroscopy. In Current Protocols in Food Analytical Chemistry (R.E. Wrolstad, ed.) pp. F1.2.1-F1.2.13, John Wiley \& Sons, New York, NY.

HALE, A.L. 2003. Screening Potato Genotypes for Antioxidant Activity, Identification of the Responsible Compounds and Differentiating Russet Norkotah Strains Using AFLP and Microsatellite Marker Analysis, Texas A\&M University, College Station, Texas, TX.

HALLIWELL, B., GUTTERIDGE, J.M.C. and CROSS, C.E. 1992. Free-radicals, antioxidants, and human-disease - where are we now. J. Lab. Clin. Med. 119, 598-620.

HAN, K.H., SHIMADA, K., SEKIKAWA, M. and FUKUSHIMA, M. 2006a. Anthocyanin-rich red potato flakes affect serum lipid peroxidation and hepatic SOD mRNA level in rats. Biosci. Biotechnol. Biochem. 71, 1356-1359.

HAN, K.H., SEKIKAWA, M., SHIMADA, K., HASHIMOTO, M., HASHIMOTO, N., NODA, T., TANAKA, H. and FUKUSHIMA, M. 2006b. Anthocyanin-rich purple potato flake extract has antioxidant capacity and improves antioxidant potential in rats. Br. J. Nutr. 96, 1125-1133.

JANSEN, G. and FLAMME, W. 2006. Coloured potatoes (Solanum tuberosum L.) - anthocyanin content and tuber quality. Genet. Resour. Crop. Evol. 53, 1321-1331.

KALT, W., FORNEY, C.F., MARTIN, A. and PRIOR, R.L. 1999. Antioxidant capacity, vitamin C, phenolics, and anthocyanins after fresh storage of small fruits. J. Agric. Food Chem. 47, 4638-4644.

KALT, W., MCDONALD, J.E. and DONNER, H. 2000. Anthocyanins, phenolics, and antioxidant capacity of processed lowbush blueberry products. J. Food Sci. 65, 390-393.

KAUR, C. and KAPOOR, H.C. 2001. Antioxidants in fruits and vegetables - the millennium's health. Int. J. Food Sci. Nutr. Technol. 36, 703-725.

LACHMAN, J., HAMOUZ, K. and ORSAK, M. 2005. Red and purple potatoes - A significant antioxidant source in human nutrition. Chem. Listy. 99, 474-482.

LEWIS, C.E., WALKER, J.R.L., LANCASTER, J.E. and SUTTON, K.H. 1998. Determination of anthocyanins, flavonoids and phenolic acids in potatoes. I: Coloured cultivars of Solanum tuberosum L. J. Sci. Food Agric. 77, 45-57.

NICOLI, M.C., ANESE, M. and PARPINEL, M. 1999. Influence of processing on the antioxidant properties of fruit and vegetables. Trends Food Sci. Technol. 10, 94-100. 
PRIOR, R.L., CAO, G.H., MARTIN, A., SOFIC, E., MCEWEN, J., O'BRIEN, C., LISCHNER, N., EHLENFELDT, M., KALT, W., KREWER, G. ET AL. 1998. Antioxidant capacity as influenced by total phenolic and anthocyanin content, maturity, and variety of Vaccinium species. J. Agric. Food Chem. 46, 2686-2693.

REDDIVARI, L., HALE, A.L. and MILLER, J.C. 2007.

Determination of phenolic content, composition and their contribution to antioxidant activity in specialty potato selections. Am. J. Potato Res. 84, 275-282.

REYES, L.F. and CISNEROS-ZEVALLOS, L. 2003. Wounding stress increases the phenolic content and antioxidant capacity of purple-flesh potatoes (Solanum tuberosum L). J. Agric. Food Chem. 51, 5296-5300.

REYES, L.F. and CISNEROS-ZEVALLOS, L. 2007. Degradation kinetics and colour of anthocyanins in aqueous extracts of purple- and red-flesh potatoes (Solanum tuberosum L.). Food Chem. 100, 885-894.

REYES, L.F., MILLER, J.C. and CISNEROS-ZEVALLOS, L. 2005. Antioxidant capacity, anthocyanins and total phenolics in purple- and red-fleshed potato (Solanum tuberosum L.) genotypes. Am. J. Potato Res. 82, 271-277.

RODRIGUEZ-SAONA, L.E., GIUSTI, M.M. and WROLSTAD, R.E. 1998. Anthocyanin pigment composition of red-fleshed potatoes. J. Food Sci. 63, 458-465.

ROSSI, M., GIUSSANI, E., MORELLI, R., LO SCALZO, R., NANI, R.C. and TORREGGIANI, D. 2003. Effect of fruit blanching on phenolics and radical scavenging activity of highbush blueberry juice. Food Res. Intern. 36, 999-1005.

SADILOVA, E., STINTZING, F.C. and CARLE, R. 2006. Thermal degradation of acylated and nonacylated anthocyanins. J. Food Sci. 71, C504-C512.
SINGH, S., GAMLATH, S. and WAKELING, L. 2007. Nutritional aspects of food extrusion: A review. Int. J. Food Sci. Nutr. Technol. 42, 916-929.

SINGLETON, V.L. and ROSSI, J.A., JR 1965. Colorimetry of total phenolics with phosphomolybdic-phosphotungstic acid reagents. Am. J. Enol. Vitic. 16, 144-158.

SWAIN, T. and HILLIS, W.E. 1959. The phenolic constituents of Prunus domestica. I. The quantitative analysis of phenolic constituents. J. Food Sci. Agri. 10, 63-68.

UYAN, S.E., BAYSAL, T., YURDAGEL, O. and EL, S.N. 2004. Effects of drying process on antioxidant activity of purple carrots. Nahrung-Food. 48, 57-60.

VAN DEN BERG, R., HAENEN, G.R.M.M., VAN DEN BERG, H. and BAST, A. 1999. Applicability of an improved Trolox equivalent antioxidant capacity (TEAC) assay for evaluation of antioxidant capacity measurements of mixtures. Food Chem. 66, 511-517.

VAN DEN BROECK, I., LUDIKHUYZE, L., WEEMAES, C., VAN LOEY, A. and HENDRICKX, M. 1998. Kinetics for isobaric-isothermal degradation of L-ascorbic acid. J. Agric. Food Chem. 46, 2001-2006.

WANG, S.W. 2002. The influence of drying and thermal treatments on antioxidant activity in asparagus. MS Thesis. Washington State University, Pullman, WA.

WANG, H., CAO, G.H. and PRIOR, R.L. 1996. Total antioxidant capacity of fruits. J. Agric. Food Chem. 44, 701-705.

WOLFE, K.L. and LIU, R.H. 2003. Apple peels as a value-added food ingredient. J. Agric. Food Chem. 51, 1676-1683. 